\title{
Reading Strategies in Persian and English Languages and Their Influence on English Reading Comprehension Ability
}

\author{
M. Rahim Bohlooli Niri ${ }^{1}$ \\ ${ }^{1}$ Department of English Language, Farhangian University, Zanjan, Iran \\ Correspondence: M. Rahim Bohlooli Niri, Department of English Language, Farhangian University, Zanjan, \\ Iran.
}

Received: September 20, 2016 Accepted: October 9, $2016 \quad$ Online Published: December 1, 2016

doi:10.5539/ijel.v6n7p159 URL: http://dx.doi.org/10.5539/ijel.v6n7p159

\begin{abstract}
The purpose of the present study is to investigate the relationship between successful readers' strategies in Persian and English languages, and the impact of instruction of such strategies on English reading comprehension ability. The present study relies on Casanave's (1998) expanded view of schema theory, the strategy schema, Goodman's (1971) language transfer or linguistic independent hypothesis and Clarke's idea of short-circuit or language ceiling hypothesis in ESL or EFL. This study also aims at finding an answer to the question of reading problem versus language problem, first raised by Alderson (1984, pp. 1-27) and then followed by Carrell (1991, pp. 159-179).
\end{abstract}

Keywords: short-circuit hypothesis, schema theory, reading strategies, transfer hypothesis, good readers, poor readers

\section{Introduction}

Reading is the most commonly needed skill in EAP (English for Academic Purposes) wordwide, not only for obtaining information but also as an enjoyable activity. Of course, reading should lead to comprehension; otherwise, it will not result in obtaining information. To read comprehensibally, the reader should gather information through certain processes. In other words, comprehension calls for deriving meaning from the printed materials. To derive meaning from the passage, the reader should first extract the meaning of words, expressions, phrases, and sentences. According to Rivers (1981) "reading is the most important activity in any language classes, not only as a source of information and a pleasurable activity but also as a means of consolidating and extending language knowledge".

In many parts of the world, having reading ability in foreign language is often important for academic studies and personal development. The overwhelming majority of societies and countries all around the world are multilingual, and educated citizens are expected to function well in more than one language. L2 reading ability, particularly in English language which is a global language and also the language of science, technology and advanced research, is considered very important in the area of academic studies. Furthermore, many people in multilingual society need to read in L2 at reasonably high levels of proficiency to achieve personal, occupational and professional goals. In modern life, learning depends largely on one's ability to interpret the printed page precisely and fully. Today people encounter materials for reading either in their first language or in a foreign language. In such a scenario, knowledge of the language in which the material is written is imperative. Hence, the ability to read for various purposes at different times in one's life is paramount for everyone. Yet despite this significance, it is a common experience that most students fail to learn to read adequately in a foreign language, and very frequently they seem to read with less understanding than our expectation.

Researchers have tried to find out the causes of poor reading. In doing so, they have faced many questions: Is it a reading problem or a language problem? Does a limited control over language short-circuit the ability to read as well? Should we develop students' reading strategies or skills? Is poor reading a matter of linguistic complexity, or does it relate to content unfamiliarity? Can the students transfer their L1 reading ability to L2 situations?

\section{Review of Literature}

In this section, I will attempt to explain the key concepts and theories underlying my study based on a review of the existing literature. 


\subsection{What Is Reading}

According to the Longman Dictionary (1992) reading is defined as perceiving a written text in order to understand its content. This can be done silently (silent reading), or by reading a written text aloud (oral reading). From a psycholinguistic viewpoint, reading is a problem solving activity involving the reader in the process of deriving and assigning meaning. Goodman (1967, pp. 126-125) defined reading as a psycholinguistic guessing game in which the reader reconstructs, as best as he/she can, the message encoded by a writer as a graphic display. According to him the act of meaning construction is an ongoing cyclical process of sampling from the input text, predicting, testing, confirming, or revising those predictions, and sampling further.

According to Rumelhart (1984) comprehension of a text is an interactive process between the reader's background knowledge and the text. Parellel to this, Rumelhart (1984) states that reading involves the reader, the text, and interaction between reader and text. Finally, Richard stated that reading is what happens when people look at a text and assign meaning to the written symbols in the text.

\subsection{Reading Purposes}

When people read, they read for a purpose. How we read and the strategies we use when reading are also determined by the purpose of reading. Reading purposes can be classified as follows:

1) Reading for survival: Reading is necessary to perform daily tasks. For example, reading instructions in order to learn how an appliance works, or how to fill out a form.

2) Reading for pleasure: We read a novel, a short story, or a newspaper article for entertainment; we also often need to read in order to solve a puzzle, or carry out some other activity which is pleasant and amusing.

3) Reading for learning: Reading to learn typically occurs in academic and professional contexts in which a person needs to learn considerable amount of information from a text.

The focus of this study is reading for learning, since EAP students also usually read material for a learning purpose. It is obvious that all students may have different purposes in their reading.

\subsection{Factors that Affect the Process of Reading}

While the various models try to explain and describe the reading process, the actual reading process may not exactly conform to any one reading model because reading is also influenced by several factors. Regarding the purpose of this study some of these factors are as follows:

Language proficiency in the L1: The level of reading proficiency that a reader has in L1 also appears to be a factor in the development of L2/F reading skills. Regarding the relationship between L1 and L2 reading, Goodman (1971) raised the Linguistic Independence Hypothesis or Language Transfer Hypothesis which claims that L1 reading ability can transfer to L2 reading situation. Royer and Carlo (1991, pp. 450-455) conclude that there is a transfer of reading skills from the L1 to L2 and that teaching reading skills in the native language may facilitate the transfer.

Language proficiency in an L2/F: L2 language proficiency is another strong factor in L2 reading. Clarke argued that weakness in L2 language competence can "short-circuit" reading performance. He believed that there must be a basic level of $L 2$ proficiency for reading of any text.

\subsection{Reading in EAP and L2 Classrooms}

According to Dudley-Evans (1998) EAP refers to any English teaching that relates to a study purpose. Students whose first language is not English may need help with both the language of academic disciplines and the specific study skills required of them during their academic course. EAP has sometimes been seen as one movement within ESP. There are four types of EAP situations:

\section{1). An English speaking country, such as UK or USA}

2). An ESL situation where English is the formal language of education and is widely spoken such as Singapore and Philipines.

3). A situation in which certain subjects such as medicine are formally taught in English, while for other subjects and at other levels of education the national language is used, such as Jordan in the Middle East.

4). A situation where all subject courses are taught in the national language, but English may be important for ancillary reasons such as the case in Iran.

\subsection{Reading Strategies}

A strategy is the mental representation of actions and consequences of actions that guide a behavior toward a 
goal. In general, the reading strategies are operations or procedures performed by a reader to achieve the goal of comprehension (Kern, 1989, pp. 140-147). According to Richard (1992) strategies can make learning more efficient and effective. According to different authors, there are many classifications for reading strategies. For example, Carrell (1989) divided reading strategies as follows:

Global strategies: Those strategies having to do with general understanding of the text;

Local strategies: Those strategies having to do with understanding detail of the text which reqire the reader to pay attention such as, sound-letter correspondence, word meaning, and sentence syntax;

Cognitive strategies: In 1967, Goodman (pp. 125-126) revolutionized the study of reading when he proposed that reading is a "psycholinguistic guessing game". According to the definition presented by Goodman, reading is a process in which readers sample the text, make hypotheses, and so forth. Here the reader rather than the text is at the heart of the reading process;

Metacognitive strategies. Metacognition is thinking about what one is doing while reading. It is simply defined as cognition about cognition or thinking about thinking.

\subsection{Reading Theories}

Various researchers have tried to explain the process of reading through the use of theories and models. In fact, many researchers attempt to create a general understanding of the reading comprehension process by means of a reasonable framework. So we often read about general models of reading. General models of reading serve useful purposes, most commonly by providing a metaphorical interpretation of the many processes involved in reading comprehension (cf. Grabe, 1999, 2000; Urquhart \& Weir, 1998). Before classifying reading models, it is useful to understand the characteristics of a good model. According to Carrell, Devine, \& Eskey (2002, p. 24) a good model has some important characteristics.

The most important of them are: 1). It can summarize the past, 2). It can help us to understand the present, and 3). It can predict the future

According to Aebersold \& Field (2001, p. 18) there are three main reading models.

1). Bottom-up theory states that the readers construct the text from the smallest units, for example from letters to words and from words to phrases and finally from phrases to sentences and so on. The process of constructing the text from these small units becomes so automatic that readers are not aware of how it operates. Decoding is an earlier term for this process. 2). Top-down theory argues that readers bring a great deal of prior acquired knowledge, assumptions, beliefs, and questions to the text. They read the given text and continue to read until the text confirms their expectations. The top-down school of reading theory argues that readers fit the text knowledge (cultural, syntactic, linguistic, and historical) to the knowledge they already possess, and then check back when new or unexpected information appears. So, these models start with hypotheses and predictions and attempt to verify them by working down to the printed stimuli. 3). The interactive school of theorists: These researchers believe that both bottom-up and top-down processes occur either alternately or at the same time. These theorists describe a process that moves both bottom-up and top-down, depending on the type of text as well as on the reader's background knowledge, language proficiency level, motivation, strategy use, and culturally shaped beliefs about reading. Reading teachers need to develop the ability to analyze bottom-up and top- down components of the reading process. This study relies on Casanave's (1988) expanded view of schema theory, the strategy schema. According to Longman Dictionary (1992) schema is the underlying structure which accounts for the organization of a text or discourse. According to Rumelhart (1984), schema is a unit of knowledge or data structure for expressing the generic concepts stored in memory.There are three kinds of schemata: content schema, formal schema, and strategy schema.

\subsection{Research Questions and Hypotheses}

I. Is there a statistically significant difference between the reading comprehension ability of the EAP students who receive reading strategies instruction beforehand and those who do not?

II. Is there any relationship between reading strategies instruction and the improvement of general English reading ability of successful readers?

III. Is there any relationship between reading strategies instruction and the improvement of general English reading ability of unsuccessful readers?

Based on the above research questions the following three null hypotheses were presented. 
1) Reading strategies instruction has no significant impact on improving the general English reading ability of Iranian EAP students.

2) Teaching reading strategies to successful readers has no significant impacts on their reading comprehension ability.

3) Reading strategies instruction to unsuccessful readers has no significant impacts on their reading comprehension.

\section{Methodology}

\subsection{Participants}

The subjects were all Iranian male students at Ardebil Islamic Azad University. This study was conducted with 148 intermediate EAP students at the mentioned university, their majors were mathematics, science, and elementary education at teacher training centre of Ardebil Branch. The subjects had passed their introductory courses, and were ready for their general English courses according to English curriculum programs for Iranian EAP students. The samples were randomly selected from different classes, and also the age, sex, and university level variables were kept constant (19-24 year old, male, and third semester students, respectively).

\subsection{Instrumentation}

Three types of tests were used to carry out the purpose of the present study.

a. Nelson Standard Test (version 200 B) for pre-intermediate students

b. Eight reading comprehension passages as pre-test and post-test

c. A questionnaire comprising two parts: the first part consisted of reading strategies in English language with forty items and the second one was with 20 reading strategies in Persian

\subsection{Design}

According to Hatch \& Farhady (1982), there are three major research designs; descriptive, correlational, and experimental. The present study is within the framework of experimental design of research, namely, pretest-posttest equivalent groups design. The schematic presentation of the above mentioned design is as follows:

\begin{tabular}{llll}
$\mathbf{R}$ & O1 & $\mathbf{X}$ & $\mathbf{O 2}$ \\
\hline $\mathbf{R}$ & O3 & $\mathbf{C}$ & $\mathbf{O 4}$
\end{tabular}

A true experimental study enjoys these characteristics: randomization, pre-testing, having experimental and control groups, and post-testing. Of course some of these characteristics are present in other research methods as well.

\subsection{Procedures}

The following procedures were taken to carry out the present study.

The researcher extracted the reading strategies of successful readers both in L1 and L2 through a questionnaire. The students were asked to read the questionnaire very carefully and choose the best answers based on their experiences. The questionnaire consisted of two sections: English questionnaire with forty reading strategies and Persian questionnaire with twenty reading strategies in Persian language. Fourteen reading strategies were chosen from each, i.e., fourteen reading strategies from English questionnaire and fourteen reading strategies from Persian, with respect to the students' obtained marks.

Then, the Nelson Standard Test (version 200B) was administered to 306 students in order to homogenize the subjects in terms of their general knowledge of basic grammar and vocabulary. Then 209 students out of 306 , whose scores fell within one standard deviation above and below the mean were selected, i.e., scores from 20 to 35 and extreme marks, namely, 67 students were excluded.

In order to have two successful/good reader groups and two unsuccessful/poor reader groups, being homogeneous pair-wise in terms of their level of reading ability, eight reading comprehension passages with 45 multiple-choice items, were administered to 239 students as a pre-test in order to verify that they enjoyed the same level of reading comprehension ability. Here again 91 subjects were excluded because their scores fell within half-standard deviation above and below the mean. These students were considered intermediate students in their reading comprehension ability and were excluded from the study. Finally, 148 subjects with respect to 
their obtained marks in reading comprehension test were selected. Seventy four subjects were considered good/successful readers because their scores were half standard deviation above the mean (26-43). The remainder namely 74 subjects were considered poor/unsuccessful readers because their scores were half standard deviation below the mean(4-16). Considering odd numbers for one and even numbers for the other group, each of the good and poor reader groups were assigned to two equally-numbered groups, i.e., A and B \& A1 and B1 each with 37 students. Groups A and A1 were called the experimental groups and groups B and B1 were called the control groups. Thus, in this study the researcher had two experimental and two control groups.

The subjects in experimental groups (one good-readers group and one poor-readers group) attended one session (100 minutes) a week for 14 weeks, i.e., one semester. In this period, they were taught the selected reading strategies both in L1 and L2 each with 14 reading strategies. As mentioned before, reading strategies were selected based on the number of students who indicated that they used them in the questionnaire of L1 and L2 as well. It should be mentioned that two reading strategies (one in L1 and one in L2) were taught to experimental groups but control groups did not receive any instruction.

Finally, the eight reading passages which were used in the pre-test, were administered as a post-test to the subjects to in all four groups. These eight passages were administered after the end of treatment, that is, after fourteen sessions, in order to investigate the effect of treatment. The experimental groups used the knowledge of reading strategies during the treatment period, whereas the two control groups did not. Exactly like the pre-test, the subjects were asked to read the passages very carefully during the allocated time (55 minutes) and to answer to 45 multiple-choice questions.

\section{Data Analysis and Discussion}

The obtained results were subjected to a test of statistical significance - analysis of variance (ANOVA) which indicates a significant difference among the four means to determine whether the reading comprehension ability of the subjects had been improved by strategies instruction (Table 1).

The assumption was that the mean of randomly assigned experimental and control groups from the same population would differ as a result of sampling error. If the difference between the means was too great to attribute to sampling error, the difference would be attributed to the treatment variable. Thus the obtained data were analyzed by performing an ANOVA, which indicated significant differences among the four means. Then a Scheffe test will be used to find out where the difference lay.

Table 1. Descriptive statistics of ANOVA

\begin{tabular}{lllllll}
\hline Source of variance & SS & D.F & M.S & F $_{\text {obs }}$ & F. critical & $\mathbf{. 0 1}$ \\
\hline Between groups & 1124.88 & 3 & 7041.62 & 601.3 & 2.68 \\
Within groups & 1686.17 & 144 & 11.70 & 6 & 3.95 \\
Total & 22811.04 & 147 & & & \\
\hline $\mathrm{P}<0.01, \mathrm{P}<0.05$ & & &
\end{tabular}

Note. $\mathrm{SS}=$ sum of square; $\mathrm{D} . \mathrm{F}=$ degree of freedom; $\mathrm{MA}=$ mean square; $\mathrm{F}_{\mathrm{obs}}=\mathrm{F}$-observed.

As the Table 1 indicates, the F (601.36) was much greater than F-critical (2.68), so it was concluded that there was a statistically significant differences between the means.

As mentioned before, the MSB (mean square between) and MSW (mean square within) are two estimates of population. The first one is an estimate based on treatment and belongs to a distribution with 3 degrees of freedom. The second estimate is unbiased for treatment and belongs to a distribution of 144 degrees of freedom. The F distribution for the interaction of 3/144 is 2.68 at 0.05 alpha level of probability and a ratio of 3.95 at 0.01 level of significance. The F-observed, i.e., 601.36, was very much greater than the critical value of F, i.e., 2.68 at 0.05 alpha level of significance and 3.95 at 0.01 level of significance. It could be concluded, therefore, that there was a statistically significant difference between the performance of four groups on doing reading comprehension tasks and such different rating could not be due to chance. As a result, the first null hypothesis was rejected by the researcher. Table 2 displays the results of Scheffe test. 
Table 2. The Scheffe test for comparing of four means

\begin{tabular}{llllll}
\hline Comparison & Mean $\mathbf{1}$ & Mean 2 & $\mathbf{t}_{\text {obs }}$ & D.F & $\mathbf{t}_{\text {cri }}$ \\
\hline $\mathbf{G}_{\mathbf{1}}$ VS. $\mathbf{G}_{\mathbf{2}}$ & 36.92 & 32.27 & $* 9.79$ & 72 & 4 \\
$\mathbf{G}_{\mathbf{1}}$ VS. $\mathbf{G}_{\mathbf{3}}$ & 36.92 & 12.70 & $* 33.27$ & 72 & 4 \\
$\mathbf{G}_{\mathbf{1}}$ VS. $\mathbf{G}_{\mathbf{4}}$ & 36.92 & 12.16 & $* 31.95$ & 72 & 4 \\
$\mathbf{G}_{\mathbf{3}}$ VS. $\mathbf{G}_{\mathbf{4}}$ & 11.71 & 11.18 & $\mathbf{6 0}$ & 72 & 4 \\
\hline
\end{tabular}

Note. $\mathbf{G}_{\mathbf{1}}=$ Experimental group (successful readers); $\mathbf{G}_{\mathbf{2}}=$ Control group (successful readers); $\mathbf{G}_{\mathbf{3}}=$ Experimental group (unsuccessful readers); $\mathbf{G}_{4}=$ Control group (unsuccessful readers); * = Indicative of significant differences.

The final step was to compare each of t-observed values. The results of table 2 show that the $\mathbf{t}_{\mathbf{o b s}}$ for group 1 and 2 is 9.72. This amount of t exceeds 4 (t-critical), so the second null hypothesis was rejected at 0.05 level of significance, at 72 degrees of freedom. Thus the researcher concluded that teaching reading strategies to successful readers has significant impacts on their reading ability. Furthermore, the comparison of group 1 and 3 and also group 1 and 4 performance confirmed the rejection of second null hypothesis too. The obtained t-observed from group 1 and $3 \&$ and group 1 and 4, i.e., 33.27 and 31.95 exceed the t-critical, so second null hypothesis was rejected.

The t-conserved value for the comparison of group 3 and 4 is $\mathbf{. 6 0}$. This amount of $t$ is lower than the critical value i.e., 4 at 72 degrees of freedom. Thus, the third null hypothesis concerning poor reading and reading strategies instruction was not rejected and the researcher concluded that strategies instruction to unsuccessful readers has no significant impact on their reading ability.

Considering reading problem versus language problem, the results showed that reading ability and reading strategies instruction is related. At low levels of reading ability, this relationship is negative. On the contrary, at high levels of reading ability, the successful readers could use reading strategies and also transfer $\mathrm{L}_{1}$ reading ability to $\mathrm{L}_{2}$ situations. According to the Clarke (1980, pp. 244-253) good readers had passed the threshold level, and thus they could benefit from their reading strategies in $\mathrm{L}_{1}$ and $\mathrm{L}_{2}$ in order to read more efficiently.

\section{Conclusion}

The findings lent support to already familiar question of reading problem versus language problem first raised by Alderson (1984, pp. 1-27) and followed by Carrell (1991). Both elements of language and reading are significant factors but the difference is that for lower level of language competence it is a matter of language problem. Conversely, at high levels of language competence it is a reading problem. The results will help the teachers to remove their students' language and reading problems. If the good readers are taught reading strategies, they will be efficient and better readers. But according to Clarke's short-circuit hypothesis (1980) the poor readers should pass a certain threshold level if they want to make use of readings strategies. Thus poor readers should be helped both with their L2, by increasing their language competence in L2, and then by teaching the reading skills.

Therefore, according to the expected results the following points will be taken into account.

1). Poor readers should be helped with their L2 i.e., language competence, and then reading strategies

2). Able readers will be more familiar with reading strategies in order to become more efficient readers

3). Teachers' duty is to enhance the students' interests. Students will not learn well and will not activate their schemata if the reading materials are not to their interest.

4). The present study will emphasize the complexity, and the importance of the reading process, urging the teachers and the students both, to look more critically at reading comprehension issue. Considering the importance of the reading process, the authors of general English books should remember to use authentic texts. The results will suggest that teachers should make the students familiar with the reading process, and students also should understand the importance of EAP reading process if they want to improve in their studies and be more knowledgeable and successful in their life.

\section{Acknowledgments}

I would like to thank Prof. Lavanya, Prof. Sailaja, and Dr. Mishra for their help during conducting the study and the manuscript preparation. I also wish to thank my dear students who willingly participated in the lengthy experiment of my project.

\section{References}

Aebersold, J. A., \& Field, L. M. (2001). From Reading to Reading Teacher: Issues and strategies for second 
language classroom. Cambridge: Cambridge University Press

Alderson, J. C. (1984). Reading in a foreign language: A reading problem or a language Problem? In J. C Alderson \& A. H. Uraquhart (Eds.), Reading in a Foreign Language (pp. 1-27). London: Longman.

Carrell, L. P., Devine, J., \& Eskey, D. E. (2002). Interactive Approaches to Second Language Reading. Cambridge: Cambridge University Press.

Carrell, P. L. (1991). Second language reading: Reading ability or language proficiency? Applied Linguistics, 12, 159-179. http://dx.doi.org/10.1093/applin/12.2.159

Casanave, C. D. (1988). Comprehension monitoring in ESL reading. A neglected essential. TESOL Quarterly, 22, 283-302. http://dx.doi.org/10.2307/3586937

Clarke, M. (1980). The short-circuit hypothesis of ESL reading. Modern Language Journal, 62(2), 244-253.

Dudley-Evans, T. (1998). Developments in English for Specific Purposes: A multi-disciplinary approach. Cambridge: Cambridge Unversity Press.

Goodman, K. (1967). Reading: A psycholinguistic guessing game. Journal of the Reading Specilist (pp. 125-126). http://dx.doi.org/10.1080/19388076709556976

Goodman, K. S. (1971). Psycholinguistic universals in the reading process. In P. Pimsleur \& T. Quinn (Eds.), The psychology of Second Language Reading. Cambridge: Cambridge University Press.

Grabe, W., \& Stoller, F. (2002). Teaching and Researching Reading. London: Peearson Education.

Hatch, E. M., \& Farhady, H. (1982). Research Design and Statistics for Applied Linguistics. Tehran: Rahnema Publications.

Kern, R. G. (1989). Second language reading strategy instruction: its effects on comprehension and word $\begin{array}{lllll}\text { inference ability. Modern } & \text { Language }\end{array}$ http://dx.doi.org/10.1111/j.1540-4781.1989.tb02535.x

Mitchell, D. C. (1982). Process of reading: A Cognitive Analysis of Fluent Reading and Learning to Read. New York: John Wiley and Sons.

Nuttal, C. (1996). Teaching Reading Skills in a Foreign Language. London: Mackmillan Heinemann English Language Teaching.

Richards, J. C., Platt, J., \& Platt, H. (1992). Longman Dictionary of Language Teaching and Applied Linguistic. London: Longman.

Rivers, W. M. (1981). Interactive Language Reading. Cambridge: Cambridge University Press.

Royer, J. M., \& Carlo, M. S. (1991). Transfer of comprehension skills from native to second language. Journal of Reading, 34(6), 450-455.

Rumelhart, D. E. (1984). Toward an interactive model of reading. In S. Dornic (Eds.), Attention and Performance. New York: Academic Press.

\section{Copyrights}

Copyright for this article is retained by the author(s), with first publication rights granted to the journal.

This is an open-access article distributed under the terms and conditions of the Creative Commons Attribution license (http://creativecommons.org/licenses/by/4.0/). 